\section{Bystander Effect Induced in Breast Cancer (MCF-7) and Human Osteoblast Cell Lines (hFOB 1.19) with HDR- Brachytherapy}

\author{
Mohd Zainudin N. H. ${ }^{1,2 \odot}$, Abdullah R. ${ }^{3,4}$, Rahman W. N. ${ }^{3 * \odot}$
}

\begin{abstract}
Background: Radiation induced bystander effects (RIBEs) occurs in unirradiated cells exhibiting indirect biological effect as a consequence of signals from other irradiated cells in the population.

Objective: In this study, bystander effects in MCF-7 breast cancer cells and hFOB 1.19 normal osteoblast cells irradiated with gamma emitting HDR Brachytherapy Ir-192 source were investigated.

Material and Methods: In this in-vitro study, bystander effect stimulation was conducted using medium transfer technique of irradiated cells to the non-irradiated bystander cells. Cell viability, reactive oxygen species (ROS) generation and colony forming assay was employed to evaluate the effect.

Results: Results indicate that the exposure to the medium irradiated MCF-7 induced significant bystander killing and decreased the survival fraction of bystander MCF-7 and hFOB from 1.19 to $81.70 \%$ and $65.44 \%$, respectively. A significant decrease in survival fraction was observed for hFOB 1.19 bystander cells $(\mathrm{p}<0.05)$. We found that the rate of hFOB 1.19 cell growth significantly decreases to $85.5 \%$ when added with media from irradiated cells. The ROS levels of bystander cells for both cell lines were observed to have an increase even after $4 \mathrm{~h}$ of treatment. Our results suggest the presence of bystander effects in unirradiated cells exposed to the irradiated medium.
\end{abstract}

Conclusion: These data provide evidence that irradiated MCF-7 breast cancer cells can induce bystander death in unirradiated MCF-7 and hFOB 1.19 bystander cells. Increase in cell death could also be mediated by the ROS generation during the irradiation with HDR brachytherapy.

Citation: Mohd Zainudin NH, Abdullah R, Rahman WN. Bystander Effect Induced in Breast Cancer (MCF-7) and Human Osteoblast Cell Lines (hFOB 1.19) with HDR-Brachytherapy. J Biomed Phys Eng. 2020;10(3):319-328. doi: 10.31661/jbpe.v0i0.1135.

\section{Keywords}

Breast Cancer; Osteoblasts; Brachytherapy; Bystander Effect; Radiation Effect

\section{Introduction}

$\mathrm{I}$ $\mathrm{n}$ the recent years, extensive investigation and research have been made towards understanding cancer development, care and treatments in order to increase the survival rates. Cancer is the second leading cause of death worldwide, and responsible for an estimated 9.6 million deaths in 2018 [1]. Globally, about 1 in 6 deaths is due to cancer. Breast cancer is the most frequent cancer and the leading cause of cancer
${ }^{1}$ PhD student, Medical Radiation Programme,

School of Health

Sciences, Universiti

Sains Malaysia, Health

Campus, Kubang Kerian,

Kelantan, Malaysia

${ }^{2}$ PhD student, Faculty of

Health Sciences, Univer-

siti Sultan Zainal Abidin,

Gong Badak Campus,

Kuala Terengganu,

Malaysia

${ }^{3} \mathrm{PhD}$, Medical Radiation

Programme, School of

Health Sciences, Uni-

versiti Sains Malaysia,

Health Campus, Kubang

Kerian, Kelantan, Ma-

laysia

${ }^{4} \mathrm{PhD}$, Department

of Nuclear Medicine,

Radiotherapy and Oncol-

ogy, Hospital Universiti

Sains Malaysia (HUSM),

Kelantan, Malaysia

*Corresponding author:

W, N. Rahman

Medical Radiation

Programme, School of

Health Sciences, Health

Campus, Universiti

Sains Malaysia, 16150

Kubang Kerian, Kelan-

tan. Malaysia

E-mail: wandiana@usm. my

Received: 2 February 2019

Accepted: 3 March 2019 
Mohd Zainudin N. H., Abdullah R., Rahman W. N.

death among females, followed by colorectal and lung cancer. In early stage of breast cancer, a standard therapy is breast-conserving surgery (BCS) followed by external beam radiotherapy irradiation (EBRT), and frequently including a local boost therapy using either electron beam or brachytherapy [2]. Electron beam or High Dose Rate (HDR) Ir192 Interstitial Brachytherapy is used as a boost in breast conservation cases after completion of EBRT. The advantages of brachytherapy boost technique result from the possibility of delivering a high dose of radiation to a limited volume of tissue in a short time period as well as decreased skin dose and potential radiobiological advantages compared with electron beam boost therapy [3, 4].

Recent advances in radiobiology and oncology have demonstrated that the radiation is an effective tool to control the localized tumours [5]. It was long believed that the biological effects of ionizing radiation were restricted to tissues within the treatment field due to direct targeting to the nucleus leading to DNA damage [6]. Radiation can directly trigger DNA single or double breaks or interact with other molecules in the cells to produce reactive oxygen species (ROS) that can diffuse and damage the critical target in the cells. Once ROS is induced, it would turn into the important signalling molecules passing around the biological effect, which cause cells damage to the untargeted cells [7]. In recent years, numerous evidence indicates that the radiation also can damage the cells not only adjacent to the tumour, but also far from the radiation track through the generation of gap-junction or cytokine-mediated cellular toxicity and also various cellular and microenvironmental signalling cascades are involved [5].

Over the years, attention in radiobiological studies has been widen to non-targeted effects of adjacent tissue surrounded the targeted area. The response of the non-irradiated cells to the radiation exposure is known as bystander effects [8]. Bystander effects describe a situation where cells, that have not been directly exposed to ionizing radiation, behave as those exposed. In consequence, they die or show chromosomal instability and other abnormalities [9]. Cells exposed to bystander signals can experience adverse effects, including cell killing, the induction of micronuclei $(\mathrm{MN})$, sister chromatid exchanges, mutations, genomic instability, changes in gene expression and cell growth, apoptosis and cell death [10-12]. The radiation-induced bystander effect (RIBE) may occurs through the transmitted signals from irradiated cells either by direct cell-to-cell contacts through gap-junction intercellular communication or by secretion of soluble factors into the medium [13-15]. Some adjacent non-irradiated cells may have a low frequency response, which may lead to undetected bystander effects. In addition, the bystander responses vary from cells to cells [16]. Some studies have also demonstrated that tumor cells are more sensitive than healthy cells in response to RIBE, resulting in an advantage in cancer treatment [17].

Bystander effects may play an important role in radiotherapy. Understanding the bystander effects can improve radiation treatment of targeted tumour and minimize the effect to healthy tissue [18]. Thus, the present in vitro study aims to examine the possibility of RIBE responses between the normal osteoblast (hFOB 1.19) and breast cancer cells (MCF-7) after the incubation with irradiated cells conditioned medium (ICCM) induced in breast cancer cells irradiated with HDR brachytherapy. The non-irradiated bystander cells viability, formation of reactive oxygen species and clonogenic ability were measured and evaluated.

\section{Material and Methods}

\section{Cell Culture}

In this in-vitro study, human breast cancer cell line (MCF-7) (ATCC $\AA$ CRL2020TM) and normal osteoblast cell lines hFOB 1.19 (ATCC® CRL8621 ${ }^{\mathrm{TM}}$ ) were used in the ex- 
periments. Cells were grown in a monolayer in tissue culture flask containing DMEM media which is supplemented with $10 \%$ fetal bovine serum and $1 \%$ antibiotics $(10,000$ units/ $\mathrm{mL}$ penicillin and $10,000 \mu \mathrm{g} / \mathrm{mL}$ streptomycin) (Gibco, Life Technologies) in humidified atmosphere of $5 \% \mathrm{CO}_{2}$ at $37^{\circ} \mathrm{C}$. The cell cultures were maintained in exponential growth as monolayers in a $75 \mathrm{~cm}^{2}$ tissue-culture flasks and subculture was performed when cells were $80 \%$ confluent using $0.25 \%$ trypsin (Gibco, Life Technologies).

The MCF-7 cell samples prepared for irradiation with HDR Brachytherapy were seeded at a density of $2 \times 10^{5}$ cells in $25 \mathrm{~cm}^{2}$ flask. The bystander cells MCF-7 and hFOB 1.19 were cultured in 96 and 6 wells plates at a density of $3 \times 10^{3}$ cells/well and $1 \times 10^{3}$ cells/well, respectively. The cells were kept in a $\mathrm{CO}_{2}$ incubator at $37^{\circ} \mathrm{C}$.

\section{Irradiation of targeted cells}

Prior to irradiation, the medium irradiated was aspirated and replaced with the fresh medium. The MCF-7 cells' confluency before irradiation was around $50-60 \%$. This range of cellular density may prevent the cell-to-cell contact and leads into only communication through the medium. The cells in flasks were placed horizontally and irradiated at room temperature with $0,0.5,1,2,4,6$ and 8 Gy with a constant dose rate in the beam field size of $15 \mathrm{~cm} \times 15 \mathrm{~cm}$. Bolus was placed on the top of the cell samples at the 'build up' depth in a water phantom. Cells irradiation were performed using HDR brachytherapy with 0.38 $\mathrm{MeV}$ gamma rays from Iridium-192 source (Nucletron, MicroSelectron). The sham-irradiated samples (0 Gy) were used as control cells subjected to similar treatment condition to the target cells.

\section{Medium transfer protocol}

After irradiation, all the cells samples (irradiated and sham-irradiated) were incubated for 1 hour. The transfer of the medium was set up according to the technique developed by Mothersill and Seymour [19]. The irradiated cell conditioned medium (ICCM) from the irradiated cells flasks were extracted and filtered through $0.22 \mu \mathrm{m}$ PES membrane filters to ensure that no cells were present in the transferred medium. The medium was then aliquoted, stored at $80^{\circ} \mathrm{C}$ deep freezer and thawed only once when it was required for cells viability, ROS and clonogenic experiments of non-irradiated bystander cells.

\section{Bystander Cell Viability Measure- ment}

Cell viability experiments were performed using PrestoBlue ${ }^{\mathrm{TM}}$ (Invitrogen, U.S.A.) cell viability reagent. PrestoBlue ${ }^{\mathrm{TM}}$ cell viability reagent is a ready-to-use reagent for rapid evaluation of the viability and proliferation of a wide range of cell types. Measurement of the bystander cell viability was conducted by seeding the cells at a density of $3 \times 10^{3}$ cells/ well in 96-well plates. This density was found to be optimal to achieve the desired confluence at the end of the exposure period for both MCF-7 and hFOB 1.19 cell lines. After 24 and 48 hours of incubation with ICCM, the samples were washed twice with PBS and then PrestoBlue ${ }^{\mathrm{TM}}$ reagent was added in each well. After 2 hours incubation at $37^{\circ} \mathrm{C}$ and $5 \% \mathrm{CO}_{2}$, the absorbance from colorimetric changes of PrestoBlue $^{\mathrm{TM}}$ reaction with viable cells were measured using microplate reader (Varioskan Flash, Thermo Scientific) at an excitation wavelength of $560 \mathrm{~nm}$ and an emission wavelength of $590 \mathrm{~nm}$.

\section{Intracellular Measurement of ROS in Bystander cells}

Intracellular ROS levels in bystander cells were measured using 2', 7' - dichlorofluorescein diacetate (DCFH-DA) (Sigma-Aldrich Pty. Ltd., St Louis, Mo, USA) upon treatment with ICCM. The study was performed in 96-wells microplates and the cells were seeded at the density of $1 \times 10^{4}$ cells $/ \mathrm{ml}$ in $100 \mu \mathrm{L}$ of respec- 
tive media. After 24 hours of plating, the cells were loaded with $2.5 \mu \mathrm{M}$ DCFH-DA for 30 minutes and incubated at $37^{\circ} \mathrm{C}$. After incubation with DCFH-DA, plates were washed with PBS twice before treatment with ICCM, and left at $37^{\circ} \mathrm{C}, 5 \% \mathrm{CO}_{2}$ incubator. The fluorescence intensities were measured after $5 \mathrm{~min}$, 1, 2, 4 and 5 hours, respectively. A microplate reader (Varioskan Flash, Thermo Scientific) was used with excitation and emission wavelengths set at $485 \mathrm{~nm}$ and $530 \mathrm{~nm}$. The relative level of ROS in the bystander cells was calculated as the mean fluorescence intensity of the cells treated with ICCM compared with the control cells without ICCM treatment.

\section{Clonogenic Assay}

The clonogenic assay measures the ability of cells to divide and produce colonies in prolong time. Appropriate number of bystander cells was plated in 6 well plates for survival analysis. After transferring the ICCM into bystander cells, they were incubated for 10 to 14 days to form colonies. Colony forming was scored under a light microscope following, fixed with iced cold methanol and stained with crystal violet. Colonies exceeding 50 cells were scored as representing surviving cells. The plating efficiency (PE) was calculated as the percentage ratio of number of colonies scored to the number of seeded cells. Surviving fraction represents the $\mathrm{PE}$ of sample relative to $\mathrm{PE}$ of control.

\section{Statistical Analysis}

All experiments were done in triplicate and each assay was repeated three times. Data was expressed as mean \pm standard error of the mean (SEM). IBM SPSS Statistics 24 was used to analyse the recorded data. One-way ANOVA was used to determine the significance of differences between cells cultured in a sham-irradiated medium and irradiated medium. Differences were considered significant when the p-values was less than 0.05 . The graph was drawn using GraphPad Prism 6.

\section{Results}

Bystander effects on MCF-7 and hFOB 1.19 cells viability

Figure 1 shows the bystander responses in the non-irradiated cells measured after 24 and 48 hours incubation with ICCM from $0,0.5$, 1, 2, 4, 6 and 8 Gy irradiated cells population. The difference between bystander cells and control groups was statistically significant $(\mathrm{p}<0.05)$ for hFOB 1.19 but not for MCF7 bystander cells $(p>0.05)$. The results have shown a consistent decrease of cell viability in hFOB 1.19 cells with increasing dose. The lowest percentage of cell viability was $85.5 \%$ in $4 \mathrm{~Gy}$ bystander cells group (Figure 1B). The cell viability of bystander cells decreased significantly in hFOB 1.19 after 48 hours treated
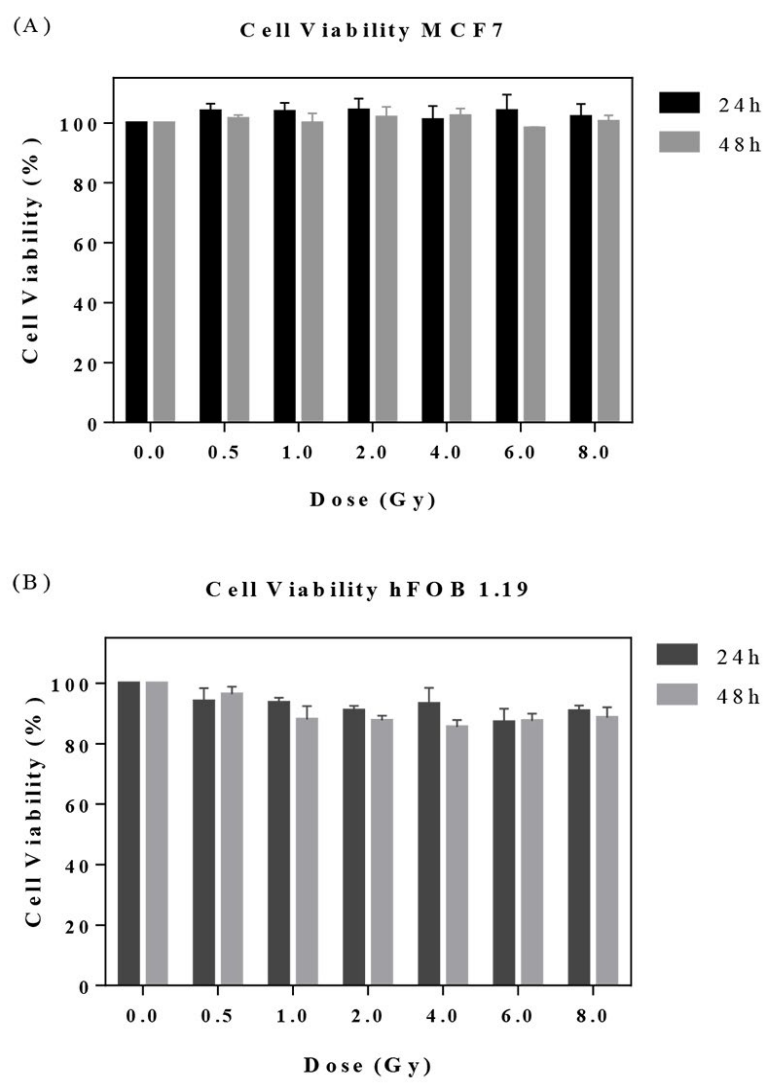

Figure 1: Percentages of bystander cells viability at different radiation doses for (A) MCF-7 and (B) hFOB 1.19 cell lines. 
with ICCM when compared to non-treated cells $(\mathrm{p}<0.05)$. However, the MCF-7 bystander cells did not show the same response. The results indicate that cell viability of MCF7 was not affected by increasing dose of irradiated cells (Figure 1A). According to the results, no significant differences in term of cell viability were observed between the $\mathrm{MCF}-7$ bystander cells, which received ICCM from irradiated cells and bystander cells, which received media from sham-irradiated cells.

\section{Intracellular ROS generation in} bystander cells

The fluorescence intensity indicating relative ROS was measured after 5 mins, 1, 2, 4 and 5 hours, respectively as shown in Figure 2. Time
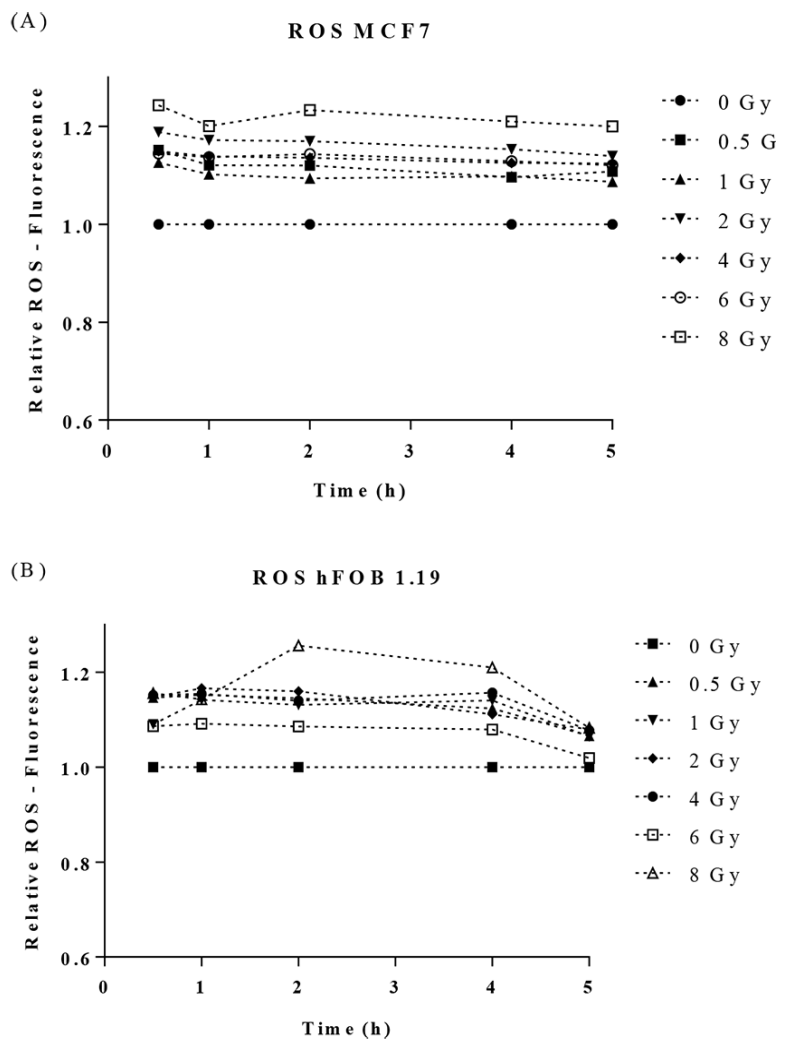

Figure 2: Fluorescence intensity level at different radiation doses for (A) MCF-7 and (B) hFOB 1.19 cell lines. Results correspond to the means \pm SE of three independent experiments with three replicates in each case. responses of intracellular ROS in the bystander cells that were treated with ICCM from MCF7 cells irradiated with radiation doses from 0 to 8 Gy were shown in Figure 2. The ROS intensity level in the bystander cells incubated with ICCM is superior than the control group for most of the bystander cells groups. Figure 2A demonstrates that the intracellular ROS of MCF-7 bystander cells consistently increases until $4 \mathrm{~h}$ of the ICCM treatment and starts to decrease at $5 \mathrm{~h}$ of the ICCM treatment. Up to 5 $h$ incubation with ICCM, the ROS intensity of all MCF-7 bystander cell groups has been still higher than control group. Meanwhile, the intracellular ROS of hFOB 1.19 bystander cells have increased approximately $25 \%$ of control at $2 \mathrm{~h}$ of the ICCM treatment and still had a similar high level at $4 \mathrm{~h}$, but it became comparable with control without ICCM treatment at $5 \mathrm{~h}$ of the ICCM treatment (Figure 2B).

\section{Clonogenic Assay}

The long-term effects of RIBE on MCF7 and hFOB 1.19 cell lines were observed through their cell survival following 10 to 14 days addition of ICCM and sham irradiated medium. Percentage of survival rates of the bystander MCF-7 and hFOB 1.19 cells incubated with ICCM were shown in Figures $3 \mathrm{~A}$ and $3 \mathrm{~B}$. The cell survival rate, in the bystander cells following treatment with ICCM, is lower than the control group for all MCF7 and hFOB 1.19 bystander cells groups. The ranges of cell survival rate for the control and bystander cells for MCF-7 and hFOB 1.19 following treatment were $81.7-100 \%$ and 65.4 - $100 \%$, respectively. The percentage of cell survival fraction in all bystander cells groups compared to the controls show no significant differences $(p>0.05)$ for MCF-7 bystander cells group. The level of cell survival shows no radiation dose dependence for all bystander cells groups. This situation indicates that the RIBE response in MCF-7 bystander cells was independent of dose. Meanwhile, the ICCM from targeted cells decreases 35\% 
Mohd Zainudin N. H., Abdullah R., Rahman W. N.

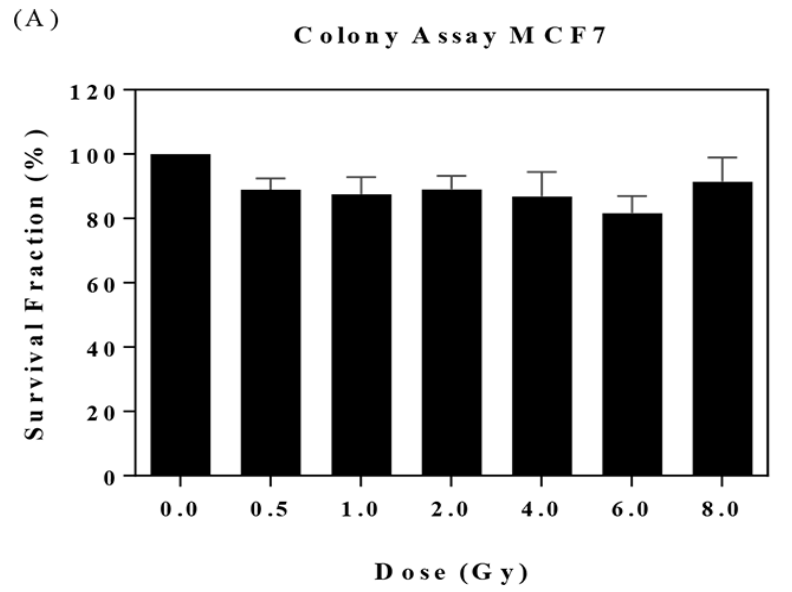

(B )

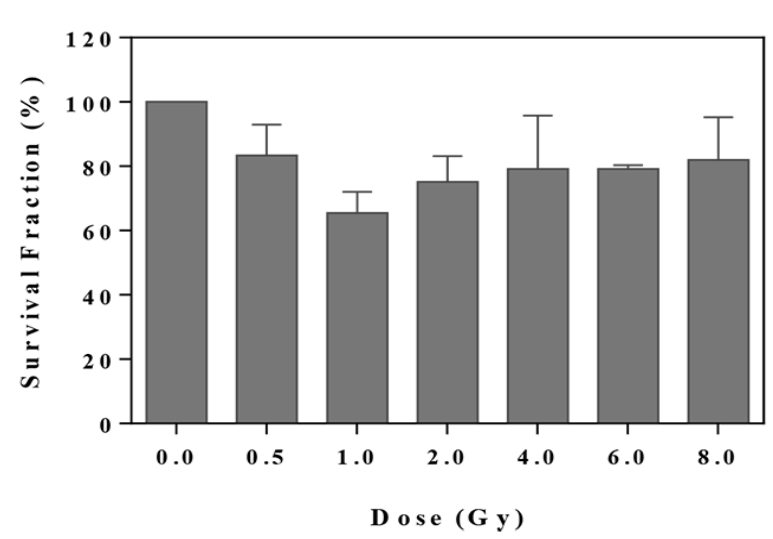

Figure 3: Percentage of survival rates of the bystander (A) MCF-7 and (B) hFOB 1.19 cell lines after addition of irradiated conditioned media (ICCM).

of the hFOB 1.19 bystander cells survival at 1 Gy treatment group, followed by a consistent increment in the cell survival up to $8 \mathrm{~Gy}$. This experiment shows the highest cells kill was in the bystander cells incubated with ICCM from 1 Gy dose for hFOB 1.19 cells. A significant difference was found in cell survival of $h F O B$ 1.19 bystander cells $(p<0.05)$. The decrement in percentage of cell survival suggests the presence of RIBE responses in bystander cells groups. Figures 4 and 5 illustrate the cell colony was stained with crystal violet for $\mathrm{MCF}-7$ and hFOB 1.19 bystander cells after $10-14$ days of treatment. Colonies with more than 50

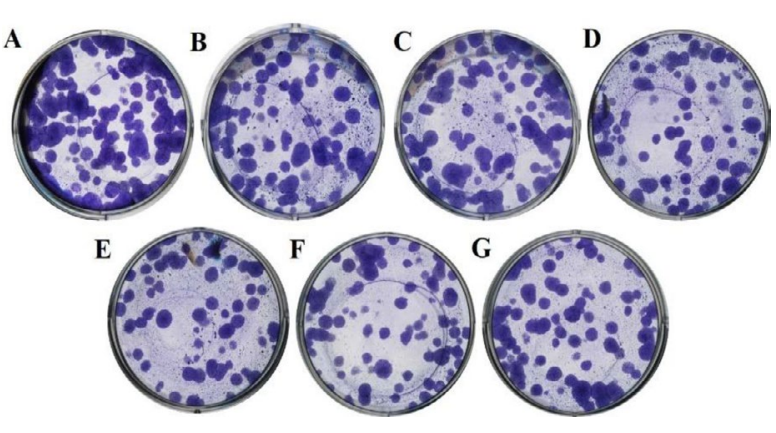

Figure 4: Cell colonies stained with crystal violet for MCF-7 bystander cells. (a) $0 \mathrm{~Gy}$, (b) $0.5 \mathrm{~Gy}$, (c) $1 \mathrm{~Gy}$, (d) $2 \mathrm{~Gy}$, (e) $4 \mathrm{~Gy}$, (f) $6 \mathrm{~Gy}$, and (g) $8 \mathrm{~Gy}$.

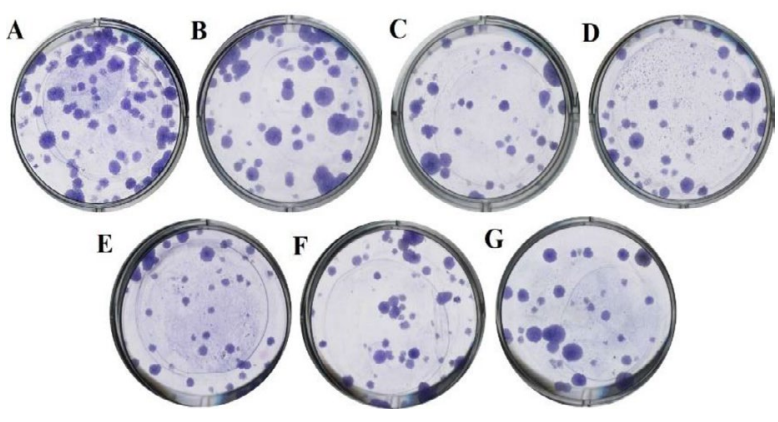

Figure 5: Cell colonies stained with crystal violet for hFOB 1.19 bystander cells. (a) $0 \mathrm{~Gy}$, (b) $0.5 \mathrm{~Gy}$, (c) $1 \mathrm{~Gy}$, (d) $2 \mathrm{~Gy}$, (e) $4 \mathrm{~Gy}$, (f) $6 \mathrm{~Gy}$, and (g) $8 \mathrm{~Gy}$.

cells were considered as representing surviving cells.

\section{Discussion}

Radiation, which induced bystander effects, have been thoroughly observed in radiotherapy of cancer. As radiation therapy is the primary technique in eliminating cancerous cells, and the study regarding bystander effects rapidly became an important topic in this field. Studies on the mechanism of bystander effects have important implications for clinical practice in radiation oncology. The present study aims to analyse the RIBE responses in normal 
and cancerous cells when were exposed to the irradiated media from breast cancer cells treated with HDR brachytherapy.

In this study, the bystander effects were studied in MCF-7 breast cancer cell line and hFOB 1.19-osteoblast cell line incubated with ICCM from MCF-7 cell irradiated with HDR Ir-192 interstitial brachytherapy at $0,0.5,1,2,4,6$ and 8 Gy doses. In a prior study, the RIBE response in MCF-7 bystander cells showed no significant differences in their cell viability and survival from control group and other different dose groups. It was shown that the radiation dose does not reduce the cell viability and survival fraction of MCF-7 bystander cells. We documented similar changes in control and non-irradiated cells, in a way that the increasing in irradiated dose would not negatively affect the cell growth. This results in accordance with other study showed the insignificant effect for MCF-7 cell line in term of short term cell proliferation and viability at $48 \mathrm{~h}$ after irradiation [18]. This present results were in line with previous study that also observed insignificant cell viability effect by any increase in the dose [13].

We observed that the RIBE response of MCF-7 bystander cells is constant and independent of dose in the dose range of $0.5-8$ Gy. This observation is consistent with the previous results obtained when the MCF-7 bystander cells were treated with the medium from targeted cells irradiated with X-ray photon beam $[13,20]$. Their results revealed the RIBE in MCF-7 cells is saturated at a dose 0.5 - $10 \mathrm{~Gy}$; however, beyond $10 \mathrm{~Gy}$, the RIBE increased. Contrary, a dose-dependent response was observed in MCF-7 bystander cells in a microbeam experiment conducted by Shao et al. [21]. It has been reported that the bystander micronuclei increased with the fraction of irradiated cells and the radiation dose delivered to the targeted cells.

In contrast, hFOB 1.19 normal osteoblast cells show that their RIBE response decreases the cell viability significantly for most of the treated groups after 24 and $48 \mathrm{~h}$ treatment. The addition of ICCM of MCF-7 irradiated cells to the hFOB 1.19 bystander cells led to increase significantly the RIBE level in both cells viability and colony forming assay. Our results were in line with previous study showing the viability of the non-irradiated osteoblast cells compared with the control cell culture decreased after the addition of 10 and $20 \%$ of ICCM from targeted cells [22]. To our knowledge, the present study is the first to show a significant responses in non-targeted effect of in-vitro breast cancer cells irradiation using HDR brachytherapy on the bystander osteoblast cells. This study demonstrates a significant reduction in the cell survival of hFOB 1.19 osteoblast cells in the dose range from 0.5 to $8 \mathrm{~Gy}$. Radiotherapy-associated bone complications have been recognized since the early application of ionizing radiation as a primary part of cancer treatment [22]. The present study investigated the gamma ray-induced ICCM-bystander effects on osteoblasts at the cellular level at clinically therapeutic doses. It is believed that the irradiated $\mathrm{MCF}-7$ cells release cytotoxic factors into the surrounding medium, resulting in the detriment on unirradiated osteoblast cells. While an enhanced RIBE in targeted cells is desirable, it is detrimental for non-targeted normal cells. Our study shows that the contribution of the bystander response to total cell damage in $\mathrm{hFOB}$ 1.19 cells was higher than that in MCF-7. In other words, this study demonstrates that the normal osteoblast cells are more sensitive than breast cancer cells in response to RIBE.

It has been reported that irradiated cells release cytotoxic factors into the surrounding medium, which may affect the unirradiated cells. The ROS, nitric oxide (NO), protein kinase as well as cytokines were believed to be involved in RIBE by the conditioned medium harvested from irradiated cells [23-25]. Previously, there were a number of studies, which reported the involvement of ROS and $\mathrm{NO}$ in many types of bystander cells through 
signalling factor after the addition of irradiated medium $[18,25,26]$. The analysis of the levels of ROS and NO in human keratinocytes $\mathrm{HaCaT}$ bystander cells was performed using real time lapse fluorescence microscopy. Jella et al., observed the consistent production of ROS up to $24 \mathrm{~h}$ and the peak level of ROS at the $1 \mathrm{~h}$ of ICCM treatment. Meanwhile, a consistent increase in NO production was observed up to 4 hours treatment and thereafter the NO measurement returned to control levels [25]. Our results demonstrate similar range of ROS production in MCF-7 and hFOB 1.19 bystander cells in which superior ROS level were observed up to $5 \mathrm{~h}$ treatment in the treated groups. The continuous generation of ROS in bystander cells could be due to the signalling molecules present in ICCM generated after irradiation.

However, ROS and NO pose a very short half-lives and short diffusion range $(<5 \mathrm{~mm})$, they may not be the direct contributors to the cellular damage in the bystander population [27]. Therefore, some long-lived bioactive factors downstream of NO and ROS such as cytokines are most likely involved in the medium-mediated bystander responses, which can induce changes of the neighboring cells $[10,28]$. Previous study makes a correlation between the generation of ROS activating a protein complex such as nuclear factor kappa $\mathrm{B}(\mathrm{NF}-\kappa \mathrm{B})$ pathway controlling transcription of DNA, cytokine production and cell survival. This would result in reduction in cell survival and proliferation by inhibiting cell death [29]. The characterising the cytokines profile of various tumour types and effect on survival of bystander cells have been reported in literature [30]. The cytokines secretion profiles of human tumour cell lines (HT1080 (fibrosarcoma), U373MG (glioblastoma), HT29 (colon carcinoma), A549 (lung adenocarcinoma) and MCF-7 (breast adenocarcinoma) were compared between acute doses of 2 and $6 \mathrm{~Gy}$ and fractionated doses of $6 \mathrm{~Gy}$ after gamma-irradiation in culture medium.
Cytokines secretion profile such as tumour necrosis factor-alpha (a) (TNF- $\alpha$ ), Interleukin 1-Beta (IL-1b), Platelet-Derived Growth Factor-AA (PDGF-A), tumour growth factorbeta-1 (TGF- $\beta 1$ ), fractalkine, Interleukin-8 (IL-8), Vascular endothelial growth factor (VEGF) and Granulocyte-colony stimulating factor (GCSF) were found in conditioned medium of all the cell lines. However, the secretion of certain cytokines was cell line-specific. The number and magnitude of secreted factors considerably varied amongst the tumour cell lines, which was dependent on incubation period. Least number of cytokines were detected in the conditioned medium of MCF-7 [30]. Similar results were found in detection of cytokines expressed in culture media from $15 \mathrm{~Gy}$ irradiated and unirradiated $\mathrm{MCF}-7$ cultures in which no significant difference was observed between treated and control group [20].

Owing to the diverse effects of cytokines secreted after irradiation, there will be a variation in the radiation induced bystander response between the growth and survival of unirradiated bystander cells. In our studies, the decrease in survival of bystander MCF-7 and hFOB 1.19 cells, suggests the increases of cytotoxic effect in ICCM, seeming to be an event associated with radiation induced signalling pathway such as the generation of ROS. The present results provide clear evidence that ROS produced in non-targeted bystander cells at a similar level in both cell lines could be the mediator of RIBE responses in both normal and cancerous cell lines.

In our study, a different response of RIBE was found in non-irradiated bystander cells, indicating that's signal from one cell type can modulate expression of bystander response in another type of cells. RIBE has important implication in tumour control using radiation therapy, in which the targeted cells can transmit the damaging signals to the non-irradiated normal and cancerous cells, thereby inducing a response similar to that of directly irradiated cells. It is important to identify the mecha- 
Bystander Effect during HDR-Brachytherapy

nisms of RIBE produce from various cell lines in order to maximize the doses to tumour tissue while reducing damage to surrounding healthy tissue during radiotherapy.

\section{Conclusion}

In conclusion, the contribution of the bystander response to the cell damage and death in hFOB 1.19 cells was higher than that in MCF-7. The observation of bystander responses was produced by MCF-7 breast cancer cells towards unirradiated normal and cancerous cells may offer new perspective for future treatment of breast cancer using HDR Brachytherapy.

\section{Acknowledgment}

This work was supported by University Sains Malaysia Research University Grant (RUI: 1001/PPSK/8012212). We acknowledge the use of the High Dose Rate Brachytherapy facility in Nuclear Medicine, Radiotherapy and Oncology Department at Universiti Sains Malaysia Hospital.

\section{Conflict of Interest}

\section{None}

\section{References}

1. Bray F, Ferlay J, Soerjomataram I, Siegel RL, Torre LA, Jemal A. Global cancer statistics 2018: GLOBOCAN estimates of incidence and mortality worldwide for 36 cancers in 185 countries. CA Cancer J Clin. 2018;68(6):394-424. doi: 10.3322/ caac.21492. PubMed PMID: 30207593.

2. Kauer-Dorner D, Berger D. The Role of Brachytherapy in the Treatment of Breast Cancer. Breast Care (Basel). 2018;13(3):157-161. doi: 10.1159/000489638. PubMed PMID: 30069174. PubMed PMCID: PMC6062670.

3. Roy S, Devleena TM, Chaudhuri P, Lahiri D, Biswas J. Tumor bed boost in breast cancer: Brachytherapy versus electron beam. Indian J Med Paediatr Oncol. 2013;34(4):257-63. doi: 10.4103/09715851.125238. PubMed PMID: 24604954. PubMed PMCID: PMC3932592.

4. Gliński B, Zabek M, Mituś M. Brachytherapy boost in women with early-stage breast cancer treated with breast conserving therapy. Reports of Practi- cal Oncology \& Radiotherapy. 2007;12(1):47-51. doi. 10.1016/S1507-1367(10)60040-5.

5. Baskar R, Dai J, Wenlong N, Yeo R, Yeoh KW. Biological response of cancer cells to radiation treatment. Front Mol Biosci. 2014;1:24. doi: 10.3389/ fmolb.2014.00024. PubMed PMID: 25988165. PubMed PMCID: PMC4429645.

6. Baskar R, Lee KA, Yeo R, Yeoh KW. Cancer and radiation therapy: current advances and future directions. Int J Med Sci. 2012;9(3):193-9. doi: 10.7150/ijms.3635. PubMed PMID: 22408567. PubMed PMCID: PMC3298009.

7. Lara GG, Andrade GF, Cipreste MF, et al. Protection of normal cells from irradiation bystander effects by silica-flufenamic acid nanoparticles. J Mater Sci Mater Med. 2018;29(8):130. doi: 10.1007/s10856018-6134-5. PubMed PMID: 30074096.

8. Marín A, Martín M, Liñán 0 , Alvarenga $F$, et al. Bystander effects and radiotherapy. Rep Pract Oncol Radiother. 2014;20(1):12-21. doi: 10.1016/j. rpor.2014.08.004. PubMed PMID: 25535579. PubMed PMCID: PMC4268598.

9. Mothersill C, Seymour CB. Radiation-induced bystander effects-implications for cancer. Nat Rev Cancer. 2004;4(2):158-64. doi: 10.1038/nrc1277. PubMed PMID: 14964312.

10. Shao C, Folkard M, Michael BD, Prise KM. Bystander signaling between glioma cells and fibroblasts targeted with counted particles. Int J Cancer. 2005;116(1):45-51. PubMed PMID: 15756683.

11. Mothersill C, Seymour C. Radiation-induced bystander effects, carcinogenesis and models. Oncogene. 2003;22(45):7028-33. doi: 10.1038/ sj.onc.1206882.

12. Mladenov E, Li F, Zhang L, Klammer H, Iliakis G. Intercellular communication of DNA damage and oxidative status underpin bystander effects. International journal of radiation biology. 2018;94(8):719-26. doi: 1080/09553002.2018.1434323.

13. Rostami A, Toossi MT, Sazgarnia A, Soleymanifard $S$. The effect of glucose-coated gold nanoparticles on radiation bystander effect induced in MCF7 and QUDB cell lines. Radiat Environ Biophys. 2016;55(4):461-466. PubMed PMID: 27613311. doi: 10.1007/s00411-016-0669-y.

14. Azzam El, De Toledo SM, Little JB. Oxidative metabolism, gap junctions and the ionizing radiation-induced bystander effect. Oncogene. 2003;22(45):7050-7. doi: 10.1038/sj.onc.1206961.

15. Iyer $R$, Lehnert $B E$. Factors underlying the cell growth-related bystander responses to $\alpha$ particles. Cancer research. 2000;60(5):1290-8. PubMed PMID: 10728689. 
Mohd Zainudin N. H., Abdullah R., Rahman W. N.

16. Mothersill C, Stamato TD, Perez ML, Cummins R, Mooney R, Seymour CB. Involvement of energy metabolism in the production of 'bystander effects' by radiation. $\mathrm{Br} J$ Cancer. 2000;82(10):17406. PubMed PMID: 10817512. PubMed PMCID: PMC2374513.

17. Gómez-Millán J, Katz IS, Farias Vde A, LinaresFernández $\mathrm{JL}$, et al. The importance of bystander effects in radiation therapy in melanoma skin-cancer cells and umbilical-cord stromal stem cells. Radiother Oncol. 2012;102(3):450-8. doi: 10.1016/j. radonc.2011.11.002. PubMed PMID: 22169765.

18. Zhang D, Zhou T, He F, Rong Y, Lee SH, Wu S, Zuo L. Reactive oxygen species formation and bystander effects in gradient irradiation on human breast cancer cells. Oncotarget. 2016;7(27):4162241636. doi: 10.18632/oncotarget.9517. PubMed PMID: 27223435. PubMed PMCID: PMC5173083.

19. Mothersill C, Seymour C. Medium from irradiated human epithelial cells but not human fibroblasts reduces the clonogenic survival of unirradiated cells. Int J Radiat Biol. 1997;71(4):421-7. PubMed PMID: 9154145.

20. Veldwijk MR, Zhang B, Wenz F, Herskind C. The biological effect of large single doses: a possible role for non-targeted effects in cell inactivation. PLOS One. 2014;9(1):e84991. doi: 10.1371/journal. PubMed PMID: 24465461. PubMed PMCID: PMC3898915.

21. Shao C, Folkard M, Held KD, Prise KM. Estrogen enhanced cell-cell signaling in breast cancer cells exposed to targeted irradiation. BMC Cancer. 2008;8:184. doi: 10.1186/1471-2407-8-184. PubMed PMID: 18590532. PubMed PMCID: PMC2443807.

22. Li XF, Zhu GY, Wang JP, Wang Y. Inhibitory effects of autologous $\gamma$-irradiated cell conditioned medium on osteoblasts in vitro. Mol Med Rep. 2015;12(1):273-80. doi: 10.3892/mmr.2015.3354. PubMed PMID: 25684548.

23. Kirolikar S, Prasannan P, Raghuram GV, Pancholi N, Saha T, et al. Prevention of radiation-induced bystander effects by agents that inactivate cell-free chromatin released from irradiated dying cells. Cell Death Disease. 2018;9(12):1142. doi: 10.1038/ s41419-018-1181-x.

24. Lyng FM, Howe OL, McClean B. Reactive oxygen species-induced release of signalling factors in irradiated cells triggers membrane signalling and calcium influx in bystander cells. International journal of radiation biology. 2011;87(7):683-95. doi: 10.3109/09553002.2010.549533.

25. Jella KK, Moriarty R, McClean B, Byrne HJ, Lyng FM. Reactive oxygen species and nitric oxide signaling in bystander cells. PloS one. 2018;13(4). doi: 10.1371/journal.pone.0195371.

26. Wang X, Zhang J, Fu J, Wang J, Ye S, Liu W, Shao C. Role of ROS-mediated autophagy in radiation-induced bystander effect of hepatoma cells. Int J Radiat Biol. 2015;91(5):452-8. doi: 10.3109/09553002.2015.1012308. PubMed PMID: 25651038.

27. Saran M, Bors W. Signalling by 02-• and NO: how far can either radical, or any specific reaction product, transmit a message under in vivo conditions? Chemico-biological interactions. 1994;90(1):3545. doi: 10.1016/0009-2797(94)90109-0.

28. Yang $S, X u$ J, Shao W, Geng $C$, Li J, et al. Radiation-induced bystander effects in A549 cells exposed to 6 MV X-rays. Cell Biochem Biophys. 2015;72(3):877-82. doi: 10.1007/s12013-0150555-2. PubMed PMID: 25686868.

29. Zhou H, Ivanov V, Lien Y, Davidson M, Hei T.Mitochondrial Function and NF- $\kappa B$ Mediated Signaling in Radiation-Induced Bystander Effects. Cancer Res. 2008;68(7): 2233-2240. doi: 10.1158/0008-5472.CAN-07-5278. PMCID: PMC3715144.

30. Desai S, Kumar A, Laskar S, Pandey BN. Cytokine profile of conditioned medium from human tumor cell lines after acute and fractionated doses of gamma radiation and its effect on survival of bystander tumor cells. Cytokine. 2013;61(1):54-62. doi: 10.1016/j.cyto.2012.08.022. PubMed PMID: 23022376 . 